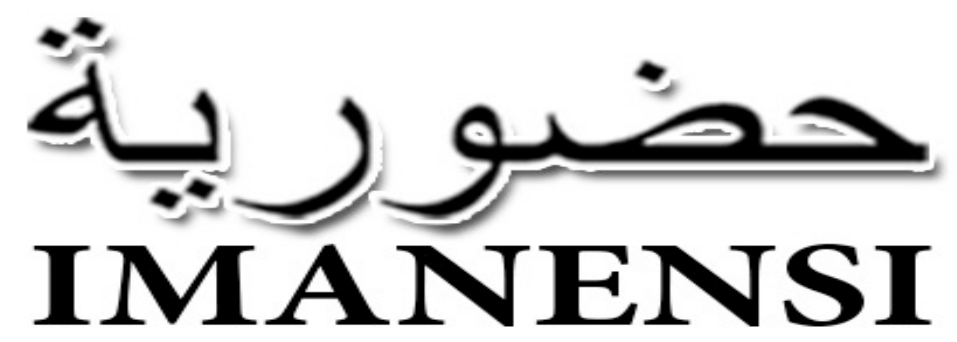

(Jurnal Ekonomi, Manajemen, dan Akuntansi Islam)

Vol 3, No 2, September 2018, Hlmn. 31-37

\title{
Al fatiha: pengingat rutin implementasi perilaku etis pelaku bisnis
}

\author{
Dessy Ekaviana \\ Universitas Brawijaya, J1. Mayjen Haryono 169 Malang, Indonesia 65145 \\ dekanprasetya@gmail.com
}

doi: 10.34202/imanensi.3.2.2018.31-37

\begin{abstract}
Abstrak
Artikel ini bertujuan untuk mengkaji peran pemaknaan Al-Fatiha bagi perilaku etis para pelaku bisnis. Pada surah Al-Fatiha dijelaskan tentang beberapa hal, yakni; hari Pembalasan, bimbingan kepada hamba-hamba-Nya agar memohon dan tunduk kepada-Nya, mengesakan-Nya dan menyucikan-Nya dari sekutu atau tandingan, bimbingan agar manusia memohon petunjuk kepada-Nya menuju jalan yang lurus, serta anjuran untuk mengerjakan kebaikan agar manusia dapat berkumpul dengan orang-orang yang beruntung di hari Kiamat kelak. Dengan demikian apabila seorang Muslim sebagai pelaku bisnis itu memahami secara baik mengenai makna dan nilai yang terkandung pada Surat Al Fatiha, maka nilai-nilai kebaikan itu akan diingat berulang-ulang dan mengakar dalam diri sehingga melahirkan etika bisnis yang baik pula.
\end{abstract}

Kata Kunci: Al-Fatiha; Etika Bisnis; Perilaku Etis.

\begin{abstract}
This article aims to examine the role of Al-Fatiha's meaning for the ethical behavior of business people. In the surah Al-Fatiha several things are explained, namely; the Day of Judgment, guidance to His servants to plead and submit to Him, impose Him and sanctify Him from allies or counterparts, guidance so that human beings ask for guidance to Him towards the right path, and advice to do good so that humans can gather with lucky people on the Day of Judgment. Thus, if a Muslim as a businessman understands well the meaning and value contained in the Letter of Al-Fatiha, then the good values will be remembered repeatedly and rooted in themselves so as to produce good business ethics.
\end{abstract}

Keywords: Al-Fatiha; Business Ethics; Ethical Behavior

This is an open access article under the CC-BY-SA license.
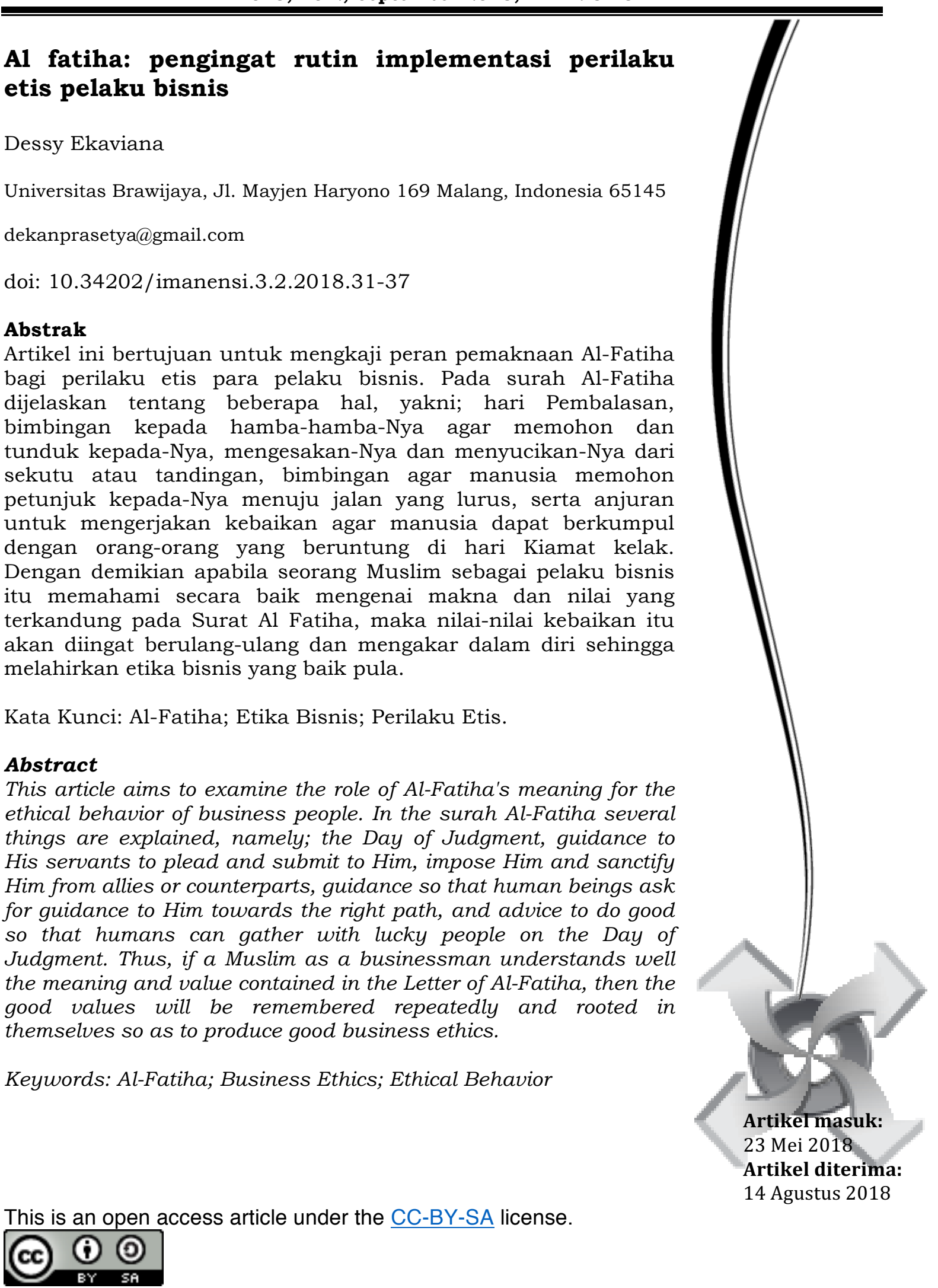
Isu mengenai etika bisnis telah menjadi perhatian yang menarik di kalangan akademisi, asosiasi professional, otoritas sipil, dan organisasi terkait lainnya selama beberapa dekade terakhir (Conroy \& Emerson, 2004; Muhammad, Fadil, Yusof, \& Amin, 2012; Quinn, 1997; White, 2008). Beberapa hal yang menyebabkan etika bisnis menjadi konsentrasi publik, perusahaan, dan akademisi adalah di Inggris terjadi kekhawatiran terkait dengan tata kelola dan perilaku perusahaan besar, didorong oleh beberapa contoh malpraktik yang dipublikasikan dengan baik seperti kasus Maxwells mengenai perampokan dana pensiun, campur tangan British Airways dengan Virgin Atlantic dan tenggelamnya Herald of Free Enterprise (Quinn, 1997). Selain kekhawatiran yang terjadi di Inggris tersebut, di Amerika juga terjadi kekhawatiran yang sama dimana kekhawatiran mengenai etika bisnis ini meningkat karena adanya kasus Enron dan Arthur Andersen serta skandal keuangan yang menjerat perusahaan besar lainnya seperti WorldCom (Conroy \& Emerson, 2004).

Etika didefinisikan sebagai konsepsi tentang perilaku atau perilaku yang benar dan adil (Carroll, 1991). Etika bisnis merupakan studi tentang kegiatan bisnis, keputusan dan situasi yang benar dan yang salah (Abdullah \& Valentine, 2009). Berkaitan dengan konsumen dan masyarakat secara umum, penelitian menunjukan bahwa etika yang baik mencerminkan bisnis yang baik pula (Joyner \& Payne, 2002). Selaras dengan (Joyner \& Payne, 2002), (Rossouw, 2005) mengemukakan bahwa etika bisnis memiliki kaitan yang erat dengan konsep tata kelola perusahaan yang baik (Good Corporate Governance). Etika merupakan bagian integral dan esensial dari tata kelola yang baik. Dari sini dapat disimpulkan bahwa standar tata kelola yang baik terkait erat dengan standar etika bisnis yang tinggi.

Konsep Good Corporate Governance muncul didorong oleh keinginan untuk mengurangi insiden berulang yang terjadi terkait dengan masalah keagenan. Konflik keagenan ini muncul karena adanya struktur kontrak organisasi yang memisahkan antara prinsipal (pemilik/ pemberi dana) dan agen (pengelola dana). Fakta yang terjadi adalah bahwa baik prinsipal sebagai pemilik maupun agen sebagai pihak yang diberi wewenang untuk mengelola perusahaan memiliki kecenderungan untuk menghindari resiko atau efek dari keputusan yang diambil (Fama \& Jensen, 1983b, 1983a). Sebagai konsekuensi, agen akan tergoda melakukan penyimpangan dari tugas pokok mereka untuk memaksimalkan kekayaan pemilik/pemberi dana.

Berbagai negara telah mengeluarkan kode terkait tata kelola perusahaan. Pemain peran lain yang dapat dan sudah memainkan peran yang berarti dalam reformasi tata kelola perusahaan di berbagai sektor bisnis antara lain adalah, World Bank, International Monetary Fund, United Nations Development Program (UNDP), Commonwealth Association for Corporate Governance (CACG), dan Organization for Economic Cooperation and Development (OECD). Formulasi kode ini dimaksudkan untuk melambangkan tentang bagaimana tata kelola perusahaan yang baik seharusnya dilaksanakan, sebagai respon dari berbagai kasus kegagalan perusahaan dan malpraktik keuangan yang terjadi.

The Financial Aspect of Corporate Governance, lebih dikenal dengan Cadbury Report 1992, memperkenalkan prinsip utama Good Corporate Governance terdiri dari keterbukaan, integritas, dan akuntabilitas. Pada tahun 1999, Organization for Economic Corporation and Development/ OECD mengemukakan bahwa prinsip dasar Good Corporate Governance adalah fairness, accountability, transparency, dan responsibility. Lebih lanjut, prinsip dasar ini kemudian berkembang menjadi transparency, accountability, responsibility, independency, dan fairness.

Meskipun telah mengalami perkembangan, beberapa penelitian empiris membuktikan bahwa prinsip dasar Good Corporate Governance yang dikemukakan oleh OECD belum mampu secara efektif mengatasi konflik keagenan yang terjadi (Chalevas \& Tzovas, 2010; M. Umer Chapra \& Ahmed, 2002; Chen, Li, \& Shapiro, 2011). (M. Umer Chapra \& Ahmed, 2002) mengemukakan bahwa pelaksanaan Good Corporate Governance belum mampu mengatasi konflik keagenan tanpa adanya komitmen moral pada masing-masing individu prinsipal maupun agen. Lebih lanjut, hasil penelitian (Chalevas \& Tzovas, 2010) menemukan bahwa pengenalan tata kelola perusahaan tidak mampu mengendalikan para manajer perusahaan dalam praktik manipulasi laba. Selaras dengan hal ini, (Chen et al., 2011) dalam penelitiannya 
menemukan bahwa prinsip dasar Good Corporate Governance masih belum mampu mengurangi konflik yang muncul dari masalah keagenan. Secara lebih rinci dijelaskan bahwa prinsip dasar Good Corporate Governance yang diformulasikan oleh OECD ini dinilai (1) tidak mampu mengurangi efek negatif dari konflik antara pemegang saham mayoritas dan pemegang saham minoritas, (2) dewan direksi, sebagai pengawas konflik antara prinsipal dan agen, biasanya bertindak secara tidak independen serta memiliki status yang rendah dan pengaruh yang lemah pada suatu perusahaan.

Berdasarkan permasalahan yang telah dikemukakan, diperlukan penyempurnaan pelaksanaan konsep Good Corporate Governance. Salah satu upaya untuk menyempurnakan fungsi dari implementasi Good Corporate Governance adalah dengan meningkatkan kualitas etika individu yang terlibat dalam mekanisme Good Corporate Governance tersebut. Chapra dan Ahmed (2002) mengemukakan bahwa ketergantungan total pada pengembangan prinsip dasar Good Corporate Governance tidak akan cukup tanpa adanya komitmen moral pada masing-masing individu baik prinsipal maupun agen. Tanpa komitmen tersebut, individu akan menemukan cara berbeda untuk melanggar hukum tanpa terdeteksi dan dihukum. Sehingga kebutuhan akan pemeriksaan dan kontrol hukum menjadi semakin banya dan meningkatkan biaya transaksi ke tingkat yang lebih tinggi. Berangkat dari permasalahan ini, penulis berpandangan bahwa perlu untuk mengkaji lebih jauh tentang peran pemaknaan Al-Fatiha bagi perilaku etis para pelaku bisnis.

\section{HASIL DAN PEMBAHASAN}

Al Fatiha dan Etika. Salah satu faktor yang mempengaruhi perilaku etis atau etika individu adalah religiusitas (Conroy \& Emerson, 2004; Kennedy \& Lawton, 1998). Pernyataan ini selaras dengan pernyataan (Miesing \& Preble, 1985) yang mengemukakan bahwa tingkat religiusitas umumnya dikaitkan dengan sikap etis yang lebih tinggi. Berkaitan dengan hal tersebut, Umat Islam memperoleh sistem etika mereka dari ajaran Al-Qur'an (yang diyakini umat Islam adalah kitab suci yang diwahyukan oleh Allah kepada Nabi Muhammad SAW di Arab abad ketujuh), dan dari sunnah (ucapan dan perilaku Nabi Muhammad SAW yang dicatat) (Rice, 1999). Berbeda dengan nilai etika yang berasal dari teori-teori konvensional, sumber nilai etika Islam tidak mengutamakan materialistis. Etika Islam didasarkan pada konsep Islam tentang kesejahteraan manusia dan kehidupan yang baik yang menekankan persaudaraan dan keadilan sosial ekonomi serta kepuasan yang seimbang dari kebutuhan material dan spiritual semua manusia (M Umar Chapra, 1992). Pada artikel ini penulis mencoba memaparkan etika bisnis Islam yang bersumber dari Q.S. Al Fatiha dalam rangka menyempurnakan praktik Good Corporate Governance yang ada.

Surat Al Fatiha merupakan surat yang paling agung dalam Al Quran (Katsir, 2006). Surat yang mulia ini terdiri dari tujuh ayat yang mengandung pujian, pemuliaan, dan sanjungan bagi Allah SWT dengan menyebut nama-nama-Nya yang baik dan sifat-sifat-Nya yang tinggi. Selain itu, surat ini juga mencakup tempat kembali manusia, yaitu hari Pembalasan. Di dalamnya juga berisi bimbingan kepada hamba-hamba-Nya agar mereka memohon dan tunduk kepada-Nya, mengesakan-Nya dan menyucikan-Nya dari sekutu atau tandingan. Lebih lanjut, di dalamnya berisi bimbingan agar manusia memohon petunjuk kepada-Nya menuju jalan yang lurus, yaitu jalan yang benar dan menetapkan mereka pada jalan tersebut. Surat ini juga mengandung anjuran untuk mengerjakan kebaikan agar manusia dapat berkumpul dengan orang-orang yang beruntung di hari Kiamat kelak.

Surat Al Fatiha oleh wajib dibaca Muslim setiap kali mereka menunaikan shalat. Tidaklah sah shalat seseorang apabila ia tidak membaca Al Fatiha di dalamnya. Seorang Muslim setidaknya membaca Surat Al Fatiha sebanyak 17 kali setiap sehari. Dengan demikian apabila seorang Muslim sebagai pelaku bisnis atau pihak yang terkait dengan praktik Good Corporate Governance itu memahami secara baik mengenai makna dan nilai yang terkandung pada Surat Al Fatiha, maka nilainilai kebaikan itu akan diingat berulang-ulang dan mengakar dalam diri sehingga 
melahirkan etika bisnis yang baik pula. Penjelasan masing-masing ayat dari Surat Al Fatihah serta kaitannya dengan pelaksanaan Good Corporate Governance adalah sebagai berikut:

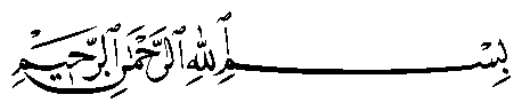

"Dengan menyebut nama Allah Yang Maha Pemurah lagi Maha Penyayang".

Salah satu keutamaan dari mengucapkan Basmallah adalah membuat syaitan menjadi kecil. Imam Ahmad bin Hanbal dalam Musnadnya meriwayatkan dari seorang yang dibonceng oleh Nabi SAW, ia berkata, "Tunggangan Nabi SAW tergelincir, maka aku katakana: 'Celakalah syaitan.' Nabi SAW bersabda: 'Janganlah engkau mengucapkan:'Celakalah syaitan.' Karena jika engkau mengucapkannya, maka ia akan membesar dan berkata: 'Dengan kekuatanku, aku jatuhkan dia'. Dan jika engkau mengucapkan 'Bismillah', maka ia akan menjadi kecil hingga seperti seekor lalat." (Ahmad V/59). Berangkat pada keutamaan tersebut, maka disunnahkan bagi setiap Muslim untuk membaca Basmallah sebelum memulai setiap pekerjaannya.

Basmallah mengandung lafadz (Allah) yang merupakan nama untuk Rabb Tabaaraka wa Ta'aala. Dikatakan bahwa Allah adalah al-ismul a'zham (nama yang paling agung), karena nama itu mengandung semua sifat. Selain itu, pada ayat pertama Surat Al Fatihah tersebut juga terdapat dua sifat Allah SWT yakni Arrahmaan dan Arrahiim (Maha Pemurah lagi Maha Penyayang). Ibnu Abbas r.a. berkata: "Keduanya adalah dua nama yang mengandung kelembutan (Al Qurthubi I/105). Ayat ini memberikan indikasi bahwa dalam segala bentuk aktivitas yang dilakukan, hendaknya manusia senantiasa melibatkan Allah di dalamnya. Jika dikaitkan dengan konsep Good Corporate Governance, maka terdapat indikasi bahwa pelaksanaan Good Corporate Governance adalah pelaksanaan tata kelola yang melibatkan nilai-nilai ketuhanan di dalamnya.

Wujud konkrit implementasi nilai ketuhanan dalam tata kelola misalnya adalah masing- masing pelaksana merasa senantiasa diawasi oleh Allah, Tuhan Yang Maha Melihat dan Maha Mengetahui. Dalam pandangan Islam, perasaan selalu diawasi oleh Allah baik lahir maupun batinnya disebut dengan Muraqabah. Jika pemaknaan mengenai muraqabah ini dipahami dengan baik, maka manusia akan menjadi lebih berhati-hati dalam menjalankan perannya di dunia ini. Pada konteks Good Corporate Governance, sebagai konsekuensi merasa diawasi oleh Allah, masing- masing pihak yang berkaitan dengan perusahaan akan berusaha sebaik mungkin dalam menjalankan perannya, sehingga konflik-konflik kepentingan yang terjadi dapat diminimalisasi.

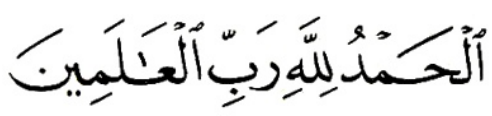

"Segala puji bagi Allah Rabb semesta alam"

Abu Ja'far bin Jarir berkata: "Makna Alhamdulillah adalah bersyukur kepada Allah SWT semata dan bukan kepada sesembahan selain-Nya, bukan juga kepada makhluk yang telah Dia ciptaka, atas segala nikmat yang Dia anugerahkan kepada para hamba-Nya yang tidak terhingga jumlahnya Tafsir Ath Thabari (I/135). Makna $A r-R a b b$ yang terdapat pada ayat kedua Surat Al Fatiha ini adalah pemilik, penguasa dan pengatur. Sedangkan Al-'aalamiin adalah jamak dari 'aalam yang berarti segala sesuatu yang ada selain Allah SWT.

Selain mengandung Al Mahabbah (mencintai),di dalamnya terdapat pengakuan bahwa Allah adalah satu-satunya pencipta, penguasa, dan pemelihara alam semesta. Hal ini juga sekaligus dijadikan sebagai peringatan dan seruan bagi setiap individu untuk menunaikan kewajiban-kewajibannya yang dapat membawa kepada kelanggenan hidup di surga kelak. Karena pada dasarnya kenikmatan yang ada adalah sama sekali bukan haknya, melainkan semata-mata karunia dari Allah. Pada konteks Good Corporate Governance, sebagai implikasi bahwa setiap yang dimiliki 
adalah bukan haknya, maka masing-masing pihak baik prinsipal maupun agen akan bertindak dan berperilaku dengan lebih bijak.

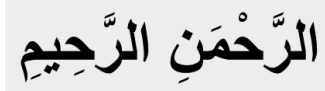

"Yang Maha Pemurah lagi Maha Penyayang"

Telah dijelaskan pada pembahasan basmallah (ayat pertama), sehingga tidak perlu diulang kembali. Pada konteks Good Corporate Governance, ayat ini memberikan indikasi bahwa setiap aktivitas yang dilakukan oleh masing-masing individu baik prinsipal maupun agen, harus dilandasi oleh rasa kasih sayang. Wujud rasa kasih saying disini diantaranya adalah dengan menghormati hak dan kewajiban masingmasing pihak sebaik mungkin serta berlaku lemah lembut ketika berinteraksi dengan mereka.

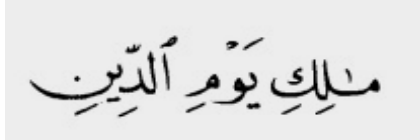

"Yang menguasai hari Pembalasan"

Hari Pembalasan adalah hari Perhitungan bagi semua makhluk, disebut juga hari kiamat. Mereka diberi balasan sesuai dengan amalnya. Jika amalnya baik, maka balasannya juga baik. Dan jika amalannya buruk, maka balasannya pun buruk kecuali bagi orang-orang yang diampuni. Ibnu Abi Hatim (I/19). Pada ayat tersebut juga terkandung makna bahwa raja yang hakiki adalah Allah SWT. Salah satu pesan yang terdapat pada ayat keempat ini adalah perintah untuk senantiasa menghisab dirinya sendiri, sebagaimana dikatakan oleh Umar r.a.: "Hisablah diri kalian sendiri sebelum kalian dihisab, dan timbanglah diri amal kalian sebelum diri (amal) kalian ditimbang. Dan bersiaplah untuk menghadapi hari yang besar, yakni hari diperlihatkannya amal seseorang, sementara semua amal kalian tidak tersembunyi dari-Nya. 'Pada hari itu kamu dihadapkan (kepada Rabb-mu), tidak ada sesuatu pun dari keadaanmu yang tersembunyi (bagi Allah)'.” (Q.S. Al-Haaqqah: 18).

Ayat ini mengindikasikan bahwa pelaksanaan Good Corporate Governance harus didasarkan pada prinsip tanggungjawab dan transparansi. Berbeda dengan konsep konvensional yang telah ada, pemaknaan tanggungjawab disini tidak hanya terbatas pada tanggungjawab horisontal; terhadap sesama makhluk hidup, tetapi juga menyangkut tanggungjawab vertikal. Tanggungjawab vertikal yang dimaksud adalah tanggungjawab kepada Allah.

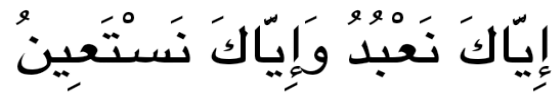

"Hanya kepada-Mu kami beribadah dan hanya kepada-Mu kami memohon pertolongan"

Menurut Bahasa, ibadah bermakna kerendahan. Adapun menurut istilah syari'at, ibadah adalah ibarat sebuah rangkaian cinta, ketundukan dan rasa takut yang sempurna. Ayat ini mengandung makna bahwa manusia hendaknya berlepas diri dari kemusyrikan dan berserah diri kepada Allah SWT semata. Ayat ini menyiratkan bahwa segala bentuk aktivitas yang dilakukan oleh manusia hendaknya bertujuan untuk beribadah kepada Allah semata. Sebagai konsekuensi tujuan beribadah, maka pelaksanaan Corporate Governance tersebut harus dilakukan dengan sebaik- baiknya sesuai dengan aturan dan kaidah yang berlaku.

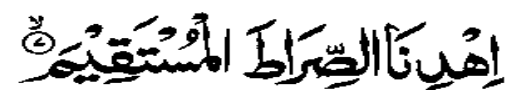

"Tunjukkanlah kepada kami jalan yang lurus” 
Setelah menyampaikan pujian kepada Allah SWT dan menyatakan hanya kepada-Nya permohonan ditujukan, maka layaklah jika hal itu diiringi dengan permintaan. Hal itu merupakan keadaan yang sangat sempurna bagi seseorang mengajukan permintaan. Pertama, ia memuji Rabb yang akan ia mintai dan kemudian memohon keperluan dirinya sendiri dan juga saudaranya dari orang-orang yang beriman. Pada ayat ini terkandung permintaan hidayah, yakni bimbingan dan taufiq.

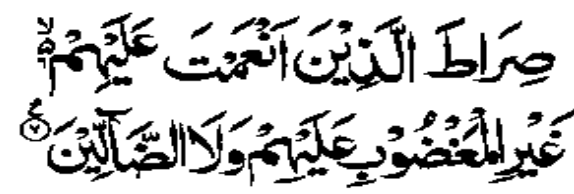

"(yaitu) jalan orang-orang yang telah Engkau anugerahkan nikmat kepada mereka; bukan (jalan) mereka yang dimurkai dan bukan (pula jalan) mereka yang sesat"

Kedua ayat ini (ayat 6 dan ayat 7) menyiratkan bahwa masing- masing individu yang terkait dengan pelaksanaan tata kelola perusahaan hendaknya senantiasa memohon petunjuk agar mampu berperilaku sesuai dengan kebenaran. Selain itu, tersirat pula bahwa masing-masing individu hendaknya tidak hanya mementingkan keperluan untuk dirinya sendiri, tetapi juga peduli terhadap kepentingan berbagai pihak lain yang terkait dengan perusahaan.

\section{SIMPULAN}

Pada surah Al-Fatiha dijelaskan tentang beberapa hal, yakni; hari Pembalasan, bimbingan kepada hamba-hamba-Nya agar memohon dan tunduk kepada-Nya, mengesakan-Nya dan menyucikan-Nya dari sekutu atau tandingan, bimbingan agar manusia memohon petunjuk kepada-Nya menuju jalan yang lurus, serta anjuran untuk mengerjakan kebaikan agar manusia dapat berkumpul dengan orang-orang yang beruntung di hari Kiamat kelak. Dengan demikian apabila seorang Muslim sebagai pelaku bisnis itu memahami secara baik mengenai makna dan nilai yang terkandung pada Surat Al Fatiha, maka nilai-nilai kebaikan itu akan diingat berulang-ulang dan mengakar dalam diri sehingga melahirkan etika bisnis yang baik pula.

\section{DAFTAR RUJUKAN}

Abdullah, H., \& Valentine, B. (2009). Realization of the kicked atom at high scaled frequencies. Middle Eastern Finance and Economics, (4), 88-96. https://doi.org/10.1103/PhysRevA.73.033420

Carroll, A. B. (1991). (Sprinkle and Maines 2010, p.450). Business Horizons, 34, 3948. https://doi.org/10.1177/0312896211432941

Chalevas, C., \& Tzovas, C. (2010). The effect of the mandatory adoption of corporate governance mechanisms on earnings manipulation, management effectiveness and firm financing: Evidence from Greece. Managerial Finance, 36(3), 257-277. https://doi.org/10.1108/03074351011019573

Chapra, M. U. (1992). Islam and The Economic System. Review of Islamic Economics (Vol. 2).

Chapra, M. U., \& Ahmed, H. (2002). Corporate Governance and Enterprise Risk Management. CORPORATE GOVERNANCE IN ISLAMIC FINANCIAL INSTITUTIONS.

Chen, V. Z., Li, J., \& Shapiro, D. M. (2011). Are OECD-prescribed "good corporate governance practices" really good in an emerging economy? Asia Pacific Journal of Management, 28(1), 115-138. https://doi.org/10.1007/s10490-010-9206-8

Conroy, S. J., \& Emerson, T. L. N. (2004). Business Ethics and Religion: Religiosity as a Predictor of Ethical Awareness among Students, 383-396.

Fama, E. F., \& Jensen, M. C. (1983a). Agency Problems and Residual Claims. Journal of Law \& Economics, 26(June 1983), 327-349. https://doi.org/10.2139/ssrn.94032 
Fama, E. F., \& Jensen, M. C. (1983b). Separation of ownership and control. Journal of Law and Economics, 26(2), 301-325. https://doi.org/10.4324/9780203888711

Joyner, B. E., \& Payne, D. (2002). Evolution and Implementation : A Study of Values, Business Ethics and Corporate Social Responsibility, 297-311.

Katsir, I. (2006). Tafsir Ibnu Katsir Jilid 1 (16th ed.). Jakarta: Pustaka Ibnu Katsir. Retrieved from www.ibnukatsir.com

Kennedy, E. J., \& Lawton, L. (1998). Religiousness and Business Ethics, 163-175.

Miesing, P., \& Preble, J. F. (1985). A comparison of five business philosophies. Journal of Business Ethics, 4(6), 465-476. https://doi.org/10.1007/BF00382609

Muhammad, M. Z., Fadil, M., Yusof, M., \& Amin, H. (2012). 3rd INTERNATIONAL CONFERENCE ON BUSINESS AND ECONOMIC ISLAMIC BUSINESS ETHICS IN SMALL AND MEDIUM ENTERPRISES ( SMES ): AN 3rd INTERNATIONAL CONFERENCE ON BUSINESS AND ECONOMIC, (March), 2427-2436.

Quinn, J. J. (1997). Personal Ethics and Business Ethics: The Ethical Attitudes of Owner / Managers of Small Business, 119-127.

Rice, G. (1999). Islamic Ethics and the Implications for Business, 345-358.

Rossouw, G. J. (2005). Business Society, 44(94), 94-106. https://doi.org/10.1177/0007650305274851

White, G. W. (2008). Journal of Business \& Finance Librarianship Business Ethics, (December 2014), 3-5. https://doi.org/10.1300/J109v06n04 